\title{
Selected diagnostic methods used in Hydroelectric Power Plants
}

\author{
Emil Golonka ${ }^{1, *}$, Michat Pająk ${ }^{1}$ and Davor K olar ${ }^{2}$ \\ ${ }^{1}$ University of Technology and Humanities in Radom, Faculty of Mechanical Engineering, \\ Stasieckiego Street 54, 26-600 Radom, Poland \\ ${ }^{2}$ University of Zagreb, Faculty of Mechanical Engineering and Naval Architecture, Ivana Lučića \\ Street 5, 10002 Zagreb, Croatia
}

\begin{abstract}
Generating electricity using Renewable Energy Sources (RES) is taking over more and more shares in the global market of energy production. This results from global energy policy which is closely related to the reduction of greenhouse gas emission and environmental pollution as well as to reducing consumption of fossil fuels. The constantly increasing number of producers of electricity from RES, such as Hydroelectric Power Plants and Small Hydroelectric Power Plants, gives an impulse for carrying out work on the development and improvement of their operation. It forces continuous work on development of technical diagnostics methods which allow to detect faults at an early stage and even, using properly designed systems, to prevent them or minimize their effects. The main task of the diagnostics and control systems is to identify any symptoms of inaccurate device operation. Next, to modify the algorithm so that the device is introduced to the area of correct operation. Detecting a defect at its initial phase gives opportunities to plan and prepare for the repair of the device. Using appropriate diagnostic methods helps to minimize the costs of major repairs and overhauls of machines and maintain the work efficiency at the desired level. This article presents selected diagnostic methods used in Hydropower Plants.
\end{abstract}

\section{Introduction}

Our whole economy has been based on fossil fuels: coal, oil and gas, of which we obtain $80 \%$ of our country's energy. Those energy sources are very efficient and easy to store in any rations needed. Those can be used whenever needed. Unfortunately, using fossil fuels carries a lot of negative consequences such as: harmful gases emission (sulphur oxides, nitrogen oxides, carbon monoxide, carbon dioxide, hydrogen chloride, hydrogen fluoride), heavy metals and dust. A nother negative feature are damages in natural environment caused by fuel extraction and its impact on natural environment e.g. open-cut mines, drilling platforms, formatting of significant waste dumps, pollution of surface waters, mining damage caused by the impact of the rock mass on structures, infrastructure, roads, agricultural and forest land [1]. A nother major aspect are also numerous accidents, some of them fatal, military conflicts over the resources, as well as ecological disasters in the form of breakdowns of oil rigs or tankers, the consequences of which are devastating for the environment and sometimes requiring even decades to neutralize them. The above presented issues are just a fraction of problems which we have to cope with while extraction and general exploitation of fossil fuels [2].

World's changing approach towards protection of the natural environment and energy production causes the urge to provide changes in the whole energetic system. Changing process is high - cost not only financially - e.g. rebuilding of infrastructure - but also

* Corresponding author: emilgolonka@ op.pl 
economically as it creates enormous challenges for countries whose economy is mainly based on fossil fuels. The world is turning to obtaining energy from renewable sources which are to provide humans with healthier and potentially inexhaustible access to it. In Polish Energy Law Act, Renewable Energy Sources (RES) are defined as: "Renewable, non-fossil energy sources including wind energy, solar energy, aerothermal energy, geothermal energy, hydrothermal energy, hydropower, wave, sea current and tidal energy, energy obtained from biomass, biogas, agricultural biogas and bioliquids" [3].

European Union (EU) is in control over the process of transformation of energy systems in its member states, obliging them to achieve individually defined goals - the percentage in shares of energy from RES in the gross final energy consumption in a given year. It is clear from Eurostat's data that the share of energy from RES is increasing every year (2004 2018) [4]. In spite of that, not all of the member countries want or are able to meet their goals, individually defined, while others are successfully implementing them above the expectations. Poland has determined its RES share of energy for 2020 at the level of $15 \%$. With all the probability, that goal will not be achieved [5]. The below diagram shows a share of the capacity of individual RES installations installed in Poland as of 2019 (\%):
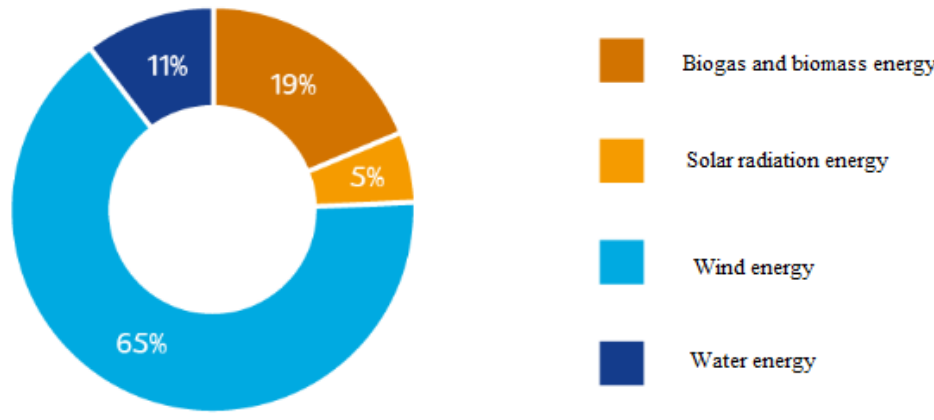

Fig. 1. Capacity of individual RES installations in Poland. credit: Energy Regulatory Office.

\section{Hydropower Plants}

Hydropower Plant is a device which changes the potential energy of flowing water to electricity. First Hydropower Plants only generated mechanical energy. In the ancient times, hydropower plants were used to grind grain and olives. L ater, they were found useful also in machine driving for example in sawmills [6]. Considering almost unlimited access to water energy (energy of sea and ocean currents as well as inland waters), hydropower engineering rates as a renewable energy source. In Poland, the term hydropower engineering (also called hydro energy, water energy) is understood primarily as the use of the potential energy of inland waters, which is caused by national geographic and climatic conditions [7]. Hydropower plants, however not as popular as solar power stations or wind farms, are the ones to generate the most power. They also are the most technically advanced endeavours. A mongst 10 of the biggest power plants in the world, 9 of them are hydropower plants. In Poland, the share of energy from renewable sources in gross final energy consumption was $12,18 \%$ (data as of 2019), 1,78\% of this production comes from hydropower [8]. The installed capacity as of June 30, 2020 in installations using hydropower is $973,858 \mathrm{M} \mathrm{W}$ [9]. The estimated technical potential of the hydropower sector in Poland is $12 \mathrm{TWh} /$ year [10].

The mechanism of operation of a hydropower plant is simple, it consists in accumulating water at a high level, with the help of dams or weirs. Then, the dammed up water is released through pipes or directly onto the turbine blades, which start to rotate. In this way, kinetic energy is transformed into mechanical energy and transferred to a generator. Generator transfers mechanical energy into electricity. The last step is to transfer 
- via transformer stations - provided electricity to the electrical grid. Energy can be stored in a large water reservoir, depending on the energy system's demand. Hydropower plants can have a power range from a few kilowatts to even a dozen gigawatts [11]. A n exemplary diagram of a hydroelectric power plant is showing in Fig. 2.

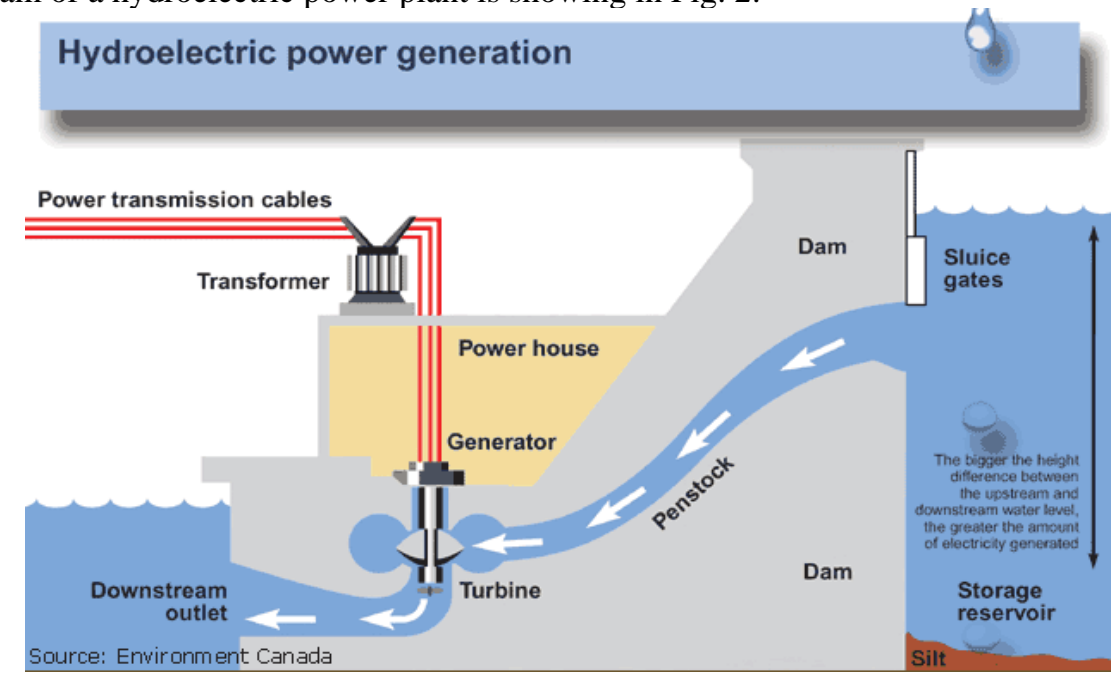

Fig. 2. Hydroelectric Power Generation.

Due to the nature of the flow, hydropower plants are divided into:

- run-of-the-river hydropower plant (without a reservoir) - the amount of the energy provided depends in the amount of water flowing in the river bed

- Control-flow (with a reservoir) power plants - with a water damming reservoir, which uses water discharge from an artificial dam or lake

- pumped storage power plant - water circulation is created artificially by the subsequent pumping of water from the lower to the upper reservoir, and then its outflow through the power plants back to the lower reservoir

- tidal power plant and ocean current power plant - using the continuous movement of sea water [11].

Next type of hydropower plant is a Small Hydropower Plant (SHP). Poland lacks an official definition of SHP, but usually this category includes installations with a total installed capacity of less than $5 \mathrm{MW}$. This definition is partly expressed in the Act on renewable energy sources, according to which SHPs with a capacity of up to $5 \mathrm{MW}$ are entitled to receive so-called green certificates.

SHP can use the potential of small rivers, agricultural retention reservoirs, irrigation systems, water supply, sewerage, transfer channels. The construction of hydrotechnical devices at SHP is simple. The buildings of these power plants are also small in size. The whole thing looks the same as ordinary farm buildings.

The basic parameters of a run-of-river hydropower plant can be determined by carrying out appropriate calculations. We calculate the power of the power plant according to the formula [6]:

where:

$$
\mathrm{N}_{\mathrm{i}}=9,81 \cdot \Sigma_{\eta} \cdot \mathrm{H}_{\mathrm{t}} \cdot \mathrm{Q}_{\mathrm{Et}},[\mathrm{kW}]
$$

$\mathrm{N}_{\mathrm{i}}$ - instantaneous power of the power plant for a given flow;

$\Sigma_{\eta}$ - product of the efficiency of individual devices (turbine, transmission, generator and possibly a block transformer);

$\mathrm{H}_{\mathrm{t}}$ - the amount of net decline for a given flow;

$\mathrm{Q}_{\mathrm{Et}}$ - the amount of instantaneous water flow through the power plant. 
The time of using the installed power of the power plant is calculated according to the formula:

$$
T_{E}=A_{E}: N_{i},[h]
$$

W e calculate the approximate value of the annual production according to the formula:

$$
A_{E}=T_{E} \cdot N_{i},[k W \cdot h / a]
$$

Due to the power criterion, we divide SHP into:

- microenergy with a power $>70 \mathrm{~kW}$

- macro energy with a power $>100 \mathrm{~kW}$

- small energy with a capacity of $<5 \mathrm{M} \mathrm{W}$

Classification due to the height of the water drop:

- low-slope with a height of $2-20 \mathrm{~m}$

- medium drop height $<150 \mathrm{~m}$

- high slopes $>150 \mathrm{~m}$

- floating on the river

- derivative (they use a derivative canal that cuts across the natural bend of the river. As a result, the height of the fall is increased. The derivative channel is equipped with a turbine) [12].

Using the hydropower potential of existing barrages brings a number of benefits. As already mentioned, hydropower plants contribute to increasing water retention by storing water above weirs. The operation of hydropower plants also contributes to counteracting the effects of floods. In this case, their influence is twofold. First, it consists in accumulating excess water in large reservoirs and preventing "flattening" the flood wave. The second way is the result of the cumulative impact of many small hydropower facilities through the intended water management in the cascade of watercourse installations. It consists in operating weirs in such a way as to retain water in the upper sections of the rivers for as long as possible and slow down its runoff as much as possible.

The use of the existing damming facilities also brings tangible benefits to the State Treasury, resulting from the reduction of the costs of maintaining rivers and damming devices and obtaining revenues from power plants operators.

The results of these researches indicate that hydropower, especially the flow power plants, is the technology with the lowest level of external costs among all the methods of energy production. Each megawatt-hour of energy generated in a RES installation - which SHP is - avoids the emission of $1,264 \mathrm{~kg}$ of carbon dioxide and $15,825 \mathrm{~kg}$ of sulphur dioxide equivalent emissions. This means that every year the energy generated in hydroelectric power plants in Poland avoids the emission of over 3 million tons of carbon dioxide and over 37 thousand tons of sul phur dioxide emissions into the atmosphere.

According to the data of the Energy Regulatory Office, among all hydropower plants existing in Poland, facilities up to $300 \mathrm{~kW}$ constitute $77 \%$ of all installations, facilities in the $300 \mathrm{~kW}-1 \mathrm{MW}$ range constitute $13 \%$, and facilities with a capacity exceeding $1 \mathrm{MW}$ only $10 \%$ of all installations.

Over $80 \%$ of the technical production potential of small hydropower plants in Poland remains unused due to historical conditions, administrative barriers and also due to the specificity of this potential [13].

\section{Technical diagnostics}

The word "diagnostics" comes from Greek, where DIA-GNOSIS meant "through recognition". Initially, this term was used only in medicine and over the years it found its use in technical processes [14]. Diagnostics deals with taking actions aimed at obtaining information about a given object and its dependence with the environment in which the object operates or, citing other sources [15], we can define diagnostics as "the operation 
science department dealing with problems related to the recognition of the technical condition of the facility without disassembly or with partial disassembly that does not affect the basic functional connections of these elements".

The aim of the technical diagnostics is to examine the technical condition of a machine or device in order to prevent failures or detect errors and correct them at an early stage, to check its efficiency and availability. It is also performed to determine the quality and efficiency of the process for which the machine is responsible. Comparison of the current machine condition to the reference state allows us to determine the quality of the process, determine the cause of errors and predict the further operation of the machine under the existing conditions.

Determination of the current technical condition of the object and detection of damage is sometimes referred to as operational diagnostics. In this case, components related to process variables are important, e.g. pressure, temperature, as well as vibroacoustics, thermal and electrical processes. Diagnostics, however, is not only the examination of visible malfunctions of machines or processes, but also - by locating the cause of the error and / or the place of damage and determining its severity - collecting information that allow you to plan the range of required equipment repairs, which can be referred to as repair diagnostics.

Depending on how the research process will be carried out, we can divide the diagnostics into 3 different groups:

- diagnostics by observation of working processes - which is performed by monitoring the parameters of these processes at a specified time and specified repeatability

- diagnostics by examining the quality of products, paying attention to the repeatability and accuracy of details, detailed quality control of products

- diagnostics by observation of residual processes - e.g. thermal, electrical, vibroacoustics processes [16].

Over the time, more and more diagnostic methods appear and, in particular, more possibilities of obtaining information from them as technical diagnostics is still developing. Development of modern technologies creates new possibilities in this field.

\section{Selected diagnostic methods used in hydroelectric power plants}

In general diagnostic methods can be divided into two groups - destructive and nondestructive diagnostic testing methods. Non-destructive diagnostic testing methods (NDT) are a set of research methods that provide information about the properties of the tested object without interfering with its structure and properties [17]. As a result, this method allows you to cut expenses and save the time of troubleshooting. The main purpose of carrying out such a test is to detect and evaluate defects that have a shape of material discontinuities. NDTs are used in numerous fields of industry thanks to the continuous development of methods and newer and more interesting possible usage. NDTs are commonly used in industries where damage to the equipment or machine parts could result in a risk of financial loss, such as transportation, pressure vessels, construction, pipelines or hoisting equipment.

On the other hand, there are destructive methods of diagnostic tests (DT) - these require interference in the structure and / or properties of the tested object. Tests are carried out on specimens taken up to their failure in order to understand the causes of damage and find out possible damage under various conditions. DTs are generally easier to carry out than NDTs. This type of research is used in case of mass-produced goods - in such a case, the destruction of one product out of hundreds produced (e.g. a car) is not economically intense. B oth DTs and NDTs have multiple methods of carrying out. 
For diagnostics purposes in an electrical industry, NDTs are used the most frequently. They let detect exploitation defects, construction material defects and object defects caused by e.g. wear materials processes. The most common defects are cracks, corrosion or effects of cavitation and erosion. NDT tests in hydoelectric power can be conducted on e.g. tanks, pipelines, turbines, bearing shells, regulator valves, stud bolts. We can list the following NDT methods: VT - visual examination (external examination usually used as preliminary one), penetration testing (PT), endoscopic examination, magnetic particle testing (MT), radiographic testing (RT), eddy-current testing (ET), ultrasonic testing (UT), thermodiagnostics. The eddy-current testing method is used, among others, to test pipes in powerplants and combined heat and power plants. NDTs are used in hydropower due to the fact that most of these methods might be effectively carried out with one-sided access to the facitlity, without the need to disassemble the elements or stopping the machine@ operation [17].

\subsection{Vibrodiagnostics}

During operation, the operated device emits a specific vibroacoustics signal, which corresponds to its technical condition. Recognizing this signal and referring it to the pattern makes it possible to determine the technical condition of the device, it can also be the basis for the implementation of appropriate operating decisions. A mong the available types of machine diagnostics (vibrodiagnostics, acoustic and visual emission, efficiency indicators, wear products), vibroacoustics tests provide us with the most data necessary to assess the technical condition of the device without forcing it to stop working. The working parts of the machine are a source of vibrations. The increasing wear of these elements results in an increase in amplitudes and a change in the nature (spectrum) of vibrations [18].

Vibrations occurring in machines may pose a direct threat to the operation of the operated machines due to rapidly progressing damage. The abnormal frequency range of changes is a clear sign of problems and, without undertaking any corrective action, an indication of an impending failure. Vibration monitoring can be continuous - preventive. Thanks to this, we gain time for comprehensive planning of the overhaul of the machine, we prevent financial losses - monitoring prevents downtime, we care for safety in the machine's working environment.

$V$ ibrodiagnostics is the basic method of testing machines that contain rotating elements and devices having rotating components such as shafts, gears, turbines and rotors. To examine the current condition of machines and devices, vibration signal analysis is often used. Requirements related to the conduct of measurements as well as evaluation criteria are included in national and international standards.

Hydropower plants connected to the power grid operate with a different load - base or peak, depending, for example, on the demand of the grid. Frequent start and stops cause exceeded degradation of water turbine components such as guide bearings. The reason for this degradation is frequent transient operation. Operating in this condition increases intensity of slide bearings' mechanical vibration. Cavitation, erosion, material defects and wear are the main types of damage associated with the astatic and transient states of HPP operation. It is necessary to predict a component degradation before it reaches its failure limits. It is also valuable to understand the relation between system performance and the degradation process. During start-ups, the turbine guide bearings (one of the most important elements of rotating machines) operate in short-term transient states. This process is associated with mechanical vibration which causes higher shaft displacement. M ost of the time it is impossible to evaluate the state of the bearing's degradation as its cannot be inspected as the HPP is still operating. Shaft vibration measurement is an observable variable used to assess the degradation state of bearings [19]. 
For vibrodiagnostics tests, the frequency analysis of the FFT signal (Fast Fourier Transformation - FFT) is used, which is based on the analysis of the vibration spectrum. In the practical use of vibrodiagnostics, an important aspect is the selection of an appropriate diagnostic method, e.g. crest factor measurement, vibration level method, spectral analysis, $\mathrm{SEE}, \mathrm{SPM}$. The method of measuring the vibration level is based on the analysis of the changes in the vibration level in a wide frequency range from 0.5 to $10 \mathrm{kHz}$. The measurement of the crest factor is the ratio of the peak value of the vibration signal to its RM S value measured in a given range of vibration frequencies.

SPM - Shock Pulse Method is a method that allows assessing the condition of the bearing [20]. SPM HD is a patented development of the shock pulse method (SPM) used for easy and quick diagnostics of the operating condition of rolling bearings. During the entire service life, the bearings generate shocks at the contact between the loaded rolling element and the raceway. These shocks are transmitted to the shock pulse transducer, which generates electrical pulses proportional to the size of the impact. The shock pulse transducer responds to a set resonant frequency (approximately $32 \mathrm{kHz}$ ), which enables the measurement of the shock pulse amplitudes. The amplitude of the shock pulse is related to three basic factors: the rolling speed (it depends on the bearing size and rotational speed), the thickness of the oil film and the condition of the bearing surfaces (damage, stress, roughness). By entering the shaft diameter and rotational speed as input with a predetermined accuracy, the effect of rolling speed on the signal is neutralized. This creates the start value of $\mathrm{HDi}$, the start of the normalized scale. The output is; HDm - scalar value in decibels. This is the basic value used to determine the degree of bearing failure. HDC scalar value in decibels. This value is responsible for 200 discharges per second. This is important in determining the condition of lubrication. HD - very useful in locating the site of potential damage in the bearing. Often it is also possible to determine the nature of the damage. The HD time signal results from very advanced digital algorithms where repetitive shocks are amplified while random signals are suppressed [21].

The SEE method (Spectral Emitted Energy) is a combination of the high-frequency vibration measurement method and the envelope analysis method. Of course, these are not all vibration-related machine testing methods. In order to correctly perform vibration measurements and interpret their results, to assess the condition of the device, it is first of all necessary to properly classify the device according to the applicable standards, because each device and machine may have different permissible vibration levels. A nother important step is to set measuring points so that the obtained results are reliable. It is also worth having a fixed schedule of periodic tests to ensure continuous and proper operation of the device [20].

The direction of development which is worth looking at is artificial intelligence. Artificial intelligence is characterized by the ability to use data logically, high computing power and the most important is the ability to learn. One of the key problems related to widespread digitization is the amount of generated data and its use. The way to achieve technological intelligence is machine learning. It is mainly about methods that allow you to gain knowledge based on the experience stored in the data. Recorded historical data is used to develop a self-learning mathematical model that predicts the behavior of a specific device. M achines will be able to use the new knowledge to search for emergency states and anomalies in the operation of devices [22].

\subsection{Thermodiagnostics}

Temperature is the oldest, and nowadays still the key indicator used in technical diagnostics of machines and devices. The diagnostic methods differ from each other in the method of taking the temperature measurement - they can be contact or contactless. The latter make it possible to read the measurement non-invasively, on the surface of the tested device, for 
example by means of thermal imaging cameras. While contact measurement methods are carried out in a way that interferes with the structure of the device, point wise, with the help of various types of sensors placed inside. The purpose of thermodiagnostics is to identify and assess the technical condition of the indicated object on the basis of temperature symptoms [23]. This goal can be achieved:

- passive method - uses the machine@ own heat generated during the operation of the device

- active method - obtaining data through artificial, external thermal stimulation and observing the reaction to it.

Generating heat is always accompanied by the process of the thermal energy flow or heat transfer. Heat transfer occurs through: radiation, conduction and convection. The total heat Qc transferred between the object and the environment can be presented as the sum:

$$
Q \mathrm{Q}=\mathrm{Qp}+\mathrm{Qk}+\mathrm{Qr},[\mathrm{J}]
$$

where:

$Q_{p}$ - the amount of heat transferred by conduction,

$Q_{k}$ - the amount of heat transferred by convection,

$Q_{r}$ - the amount of heat transferred by radiation.

Contact methods of temperature measurement use thermometers, i.e. sensors of various structures. Usually, the principle of their operation is to convert a non-electrical quantity, i.e. temperature, into electrical quantity. The method and place of the sensor placing on the tested object have a great influence on the measurement accuracy. The selection of a thermometer is usually made on the basis of its accuracy and measuring range.

Thermoelectric sensors (thermocouples) are commonly used to measure temperature on devices in the energy industry. When measuring the temperature of the turbine set bearings, it is recommended to use $\mathrm{K}$, J thermocouples or a Pt100 thermoresistor. In practice, the temperature measurements of the lower shells of the plain bearings are made (one or two points on one bearing shell) and the temperature of the thrust bearing. The sensors are connected to the measuring amplifier, hence the current signal proportional to the measured temperature is transmitted to the processing systems and then to the protection and diagnostic systems. Figure 3 shows the method of measuring temperature differences in thick-walled turbine or valve bodies using thermocouple probes.

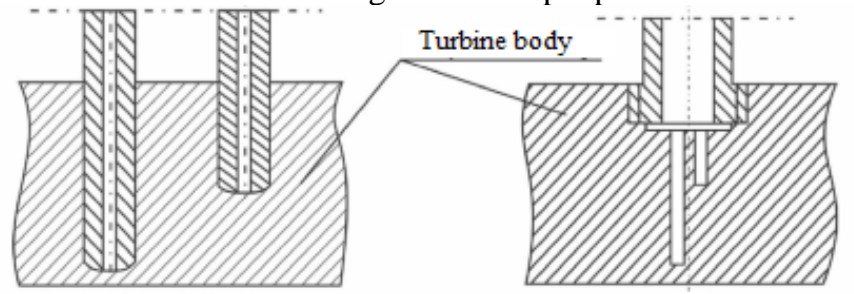

Fig. 3. Example of measuring temperature differences in thick-walled turbine or valve bodies.

Cases of devices operating in the power industry reach high temperatures. Thermocouples measure up to $450^{\circ} \mathrm{C}$. The temperature difference does not usually exceed $50^{\circ} \mathrm{C}$ within the thickness of the metal body.For such measuremens, the desired accuracy is on the level of about $2 \%$. In thermodiagnostics of turbine sets, high reliability of the measuring devices which are used is required, because it is only possible to replace them during the repairs. The advantages of contact thermometers are: high reliability, relatively simple structure, low cost and simple measuring system.

A mong the non-contact temperature measurement devices in the energy industry, we can list those that record the temperature distribution on the surface of the tested device or measure the temperature at a specific point. These devices operate by registering the infrared radiation emitted by the tested object. For point measurements, pyrometers and 
special measuring heads are used. These devices consist of an infrared detector, an optical system and an electronic module that converts an electrical signal into a temperature value. A thermal imaging device called thermal imaging or thermographic cameras is used to study the temperature distribution on the tested surface. These devices enable the registration and visualization of temperature distribution in the form of colored thermograms. The thermodiagnostic (non-contact) test records the temperature distribution on the surface and is often also performed during regular equipment maintenance. It enables the detection of symptoms of an impending failure. On the basis of the thermograph, it is possible to indicate the source of the problem or, by locating points of significantly different temperature, precisely place additional diagnostic devices [23]. A standard appearance is the release of heat by devices as a result of friction or electric current flow, and it is already taken into account in the design of the device (cooling systems, lubricants reducing friction are used). In hydroelectric power plants, thermodiagnostic tests are carried out on such elements as: electric motors, power generators, bearings (pumps, shafts, generators, electric motors), transformer stations, electric cables, fuses and electrical connectors. In electric motors and generators, the thermal imaging test can detect: seizure of bearings, overheating, breakdown of the rotor or stator insulation, damage to electrical connections as well as misalignment of shafts, e.g. coupling. The figure 4 shows an image from the thermal imaging camera of the engine with the damaged bearing visible. Errors in electrical installations, e.g. excessively strained, damaged, loose or with corroded cables, fuses close to blown or already blown cause anomalies in the thermal image [24].

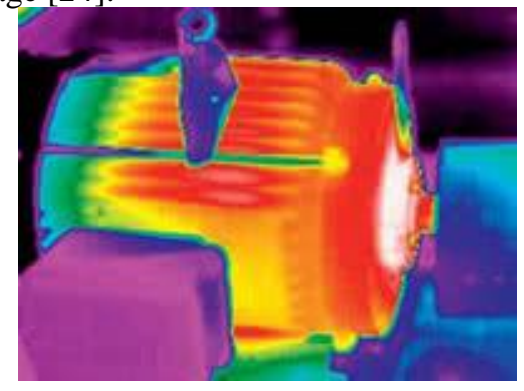

Fig. 4. The engine with the damaged bearing visible [24].

\section{Conclusions}

The constant development of technology, as was emphasized several times above, opens up more and more opportunities in the field of technical diagnostics over time. They are also enforced by increasingly stringent safety and reliability standards.

At a time when attempts are made to reduce the effects of human interference in the natural environment, it is a natural step to turn to renewable energy. In this case hydropower plants. The more developed the diagnostics, the lower the risk of failure and further damage to the environment. It is also a way of ensuring the safety of facility operation. The more energy is produced from RES, the less we use fossil fuels, and this has many positive effects for us people and the environment.

This article presented (chapter 2) the construction and operation scheme of hydropower plants, their classification according to various criteria, as well as the basic advantages of hydropower. The essence and purpose of diagnostics is briefly presented, along with the basic division according to the mode of action (chapter 3 ). The selected methods of technical diagnostics mentioned in the title and examples of their application in hydroelectric power plants have been divided into non-destructive and destructive testing methods (chapter 4). Particular attention was devoted to the issue of vibrodiagnostics and thermo-diagnostics. 


\section{References}

1. J. Bednorz, Górnictwo i Geologia, V . 6, editon 4, 2 (2011)

2. M. Popkiewicz, Rewolucja energetyczna: A le po co?, chapt. 7, 14 (2015)

3. Ustawa z dnia 20 lutego 2015 r. o odnawialnych źródłach energii (Dz. U. z 2015 r. nr 2015, poz. 478)

4. Eurostat newsrel ease, V. 17/2020, 1-3 (2020)

5. P. Wróbel, M. Ścigan, Cel OZE na 2020: co się stanie, jeśli Polska go nie osiągnie? (2020)

6. M. Hoffman, Małe elektrownie wodne - poradnik, chapt. 2 (1992)

7. J. M azurkiewicz, OZE Energetyka Wodna (2018)

8. K. Walkowska, Energia ze źródeł odnawialnych w 2019 r., 1-2 (2020)

9. Urząd Regulacji Energetyki, Moc zainstalowana, stan na dzień 30.06.2020 (2020)

10. A. Bednarska, Hydroenergetyka w Polsce - obecna sytuacja i perspektywy na przyszłość (2010)

11. J. M azurkiewicz, OZE E nergetyka Wodna (2018)

12. Powiat Kielce, Małe elektrownie wodne, 1-2 (2019)

13. Raport Global Compact Network Poland \& MGMiŻŚ, Zarządzanie zasobami Wodnymi w Polsce, 104-108 (2018)

14. J. Blata, J. J uraszek, M etody diagnostyki technicznej teoria i praktyka (2013)

15. M. Hebda, S. Niziński, H. Pelc, Podstawy diagnostyki pojazdów mechanicznych, chapt. 1 (1980)

16. B. Żółtowski, M. Łukasiewicz, Diagnostyka drganiowa maszyn, chapt. 1 (2012)

17. P. Zientek, Napędy i sterowanie, V. 3, 114-119 (2017)

18. S. Legutko, Podstawy eksploatacji maszyn i urządzeń, 48-49 (2004)

19. G. Pino, J.R. Ribas, J.M. Guimarães, Shock and Vibration, V. 2018, article ID 5981089 (2018)

20. T. Kurzacz, Główny Mechanik, V. March-April, 42-46 (2018)

21. Shock Pulse Monitoring HD, measuring techniques https://www.spminstrument.com/measuring-techniques/shock-pulse-monitoring/spmhd/\#technical

22. Transition Technologies, Sztuczna inteligencja, czyli rewolucja dla fabryk i elektrowni (2017)

23. M. Fidali, Szkieletowy system doradczy DiaDyn, chapt. 11, 131-138 (2008)

24. M. Jaworowska, A PA - automatyka, podzespoły, aplikacje, V. 54, 36-41 (2011) 